\title{
Microwave Microblocks Sealing with High-Frequency Soldering
}

\author{
Yuriy N. Grishchenko and Vladimir L. Lanin* \\ Belarusian State University \\ of Informatics and Radioelectronics \\ 6 P. Brovki Str., Minsk, 220013, Republic of Belarus
}

Received 18.06.2018, received in revised form 03.07.2018, accepted 13.07.2018

Developed technology sealing microblocks microwave made of aluminum alloys, using high-frequency (HF) soldering, which provides high speed and selectivity heating. Are methods select the frequencies of heating, evaluation of tension electromagnetic fields in the working area inductor, as well as the experimental temperature-time dependence of high-frequency soldering. A number of parameters of the inductor are calculated: the frequency of electromagnetic oscillations is in the range 440-2200 kHz; the effective power of $\mathrm{HF}$ heating for these frequencies is in the range $0,8 \div 2,0 \mathrm{~kW}$. The temperature profile of the high-frequency soldering of the packages of the microwave microblocks and the intensity both inside the inductor and inside the microwave casing of the microblock were investigated. The developed technological process of hermetic sealing of microblock packages includes the operations: preparation of packages and covers for soldering, assembly of the casing in the device, high-frequency brazing, quality control of the soldered joint and hermetic sealing of the package. Experimental time dependences of the temperature in the HF solder zone on time, the magnetic field strength on the power of the HF generator, and the temperature of the substrate inside the housing are obtained.

Keywords: high-frequency heating, effects of heating, sealing, microblocks, soldering.

Citation: Grishchenko Yu.N., Lanin V.L. Microwave microblocks sealing with high-frequency soldering, J. Sib. Fed. Univ. Eng. technol., 2018, 11(6), 659-670. DOI: 10.17516/1999-494X-0083.

\section{Герметизация микроблоков СВЧ}

\section{высокочастотной пайкой}

Ю.Н. Грищенко, В.Л. Ланин

Белорусский государственный

университет информатики и радиоэлектроники Республика Беларусь, 220013, Минск, ул. П. Бровки, 6

Разработана технология герметизации микроблоков СВЧ, изготовленных из алюминиевых сплавов, с применением высокочастотной (ВЧ) пайки, которая обеспечивает высокую

(C) Siberian Federal University. All rights reserved

This work is licensed under a Creative Commons Attribution-NonCommercial 4.0 International License (CC BY-NC 4.0)

* Corresponding author E-mail address: vlanin@bsuir.by 
скорость и избирательность нагрева. Предложены методики выбора частоты нагрева, оценки напряженности электромагнитного поля в рабочей зоне индуктора, а также получень экспериментальные температурно-временные зависимости высокочастотной пайки. Рассчитаны параметры индуктора, частота электромагнитных колебаний, которая находится в диапазоне 440-2200 кГи; эффрективная мощность ВЧ-нагрева - в диапазоне 0,8 $\div$ 2,0 кВт. Исследованы температурные профили ВЧ-пайки корпусов СВЧ микроблоков и напряженность поля как внутри индуктора, так и внутри корпуса микроблока. Разработанный технологический процесс герметизации корпусов микроблоков включает операции подготовки корпусов и крышек к пайке, сборку корпуса в приспособлении, ВЧ-пайку, контроль качества паяного шва и герметичности корпуса. Получены экспериментальные временные зависимости температуры в зоне ВЧ-пайки, напряженности магнитного поля от мощности ВЧ-генератора и температуры подложки, находящейся внутри корпуса.

Ключевые слова: высокочастотный нагрев, эффекты нагрева, герметизация, корпуса микроблоков, пайка.

\section{Введение}

Микроминиатюризация РЭА в значительной степени зависит от создания функциональных приборов и блоков в микроэлектронном исполнении, помещенных в общий герметичный корпус. Микроблоки СВЧ-диапазона нашли широкое применение в аэрокосмической технике, средствах телекоммуникаций, мобильных устройствах управления и др. Основными достоинствами микроблоков с общей герметизацией (МБОГ) являются следующие:

- повышение уровня интеграции и плотности компоновки в 5-10 раз объединением электронных модулей, индикаторных, оптико- и электромеханических устройств, антенн в одном корпусе;

- применение тонко- и толстопленочных БГИС и микросборок СВЧ-диапазона, пленочной и печатной коммутации, корпусных электронных компонентов, не имеющих аналогов в микроисполнении;

- улучшение тепловых характеристик ввиду значительно большей поверхности теплоотдачи корпуса МБОГ и возможности использования устройств искусственного охлаждения;

- ремонтопригодность, наличие доступа к регулируемым и подстраиваемым компонентам, внутриблочному монтажу, возможность замены микроплат;

- наличие общего экранирования в корпусе МБОГ и возможность реализации межплатного и внутриплатного экранирования;

- высокая надежность вследствие коротких трасс внутриблочного монтажа, что исключает два-три структурных уровня электрических соединений и в 7-10 раз уменьшает длину пути электрического сигнала по сравнению с аппаратурой III поколения [1].

Источники вторичного электропитания в корпусе МБОГ имеют рассеиваемую мощность 100-150 Вт/дм² при плате на поликоре ВК-100-1 и 200-300 Вт/дм² - на анодированном алюминии. Микроблоки питания применяются в качестве DC/DC-преобразователей бортовой космической аппаратуры мощностью до 120 Вт. Они получают энергию от шины питания постоянным напряжением 20-120 В, соединенной с солнечными батареями, и преобразуют в напряжение от 3 до 27 В постоянного тока, необходимое для электронной аппаратуры. Преобразователи должны устойчиво работать в условиях воздействия ионизирующих излучений космического пространства при дозе до $38 \mathrm{MэB} \cdot \mathrm{cm}^{2} /$ год и ударных механических нагрузок до $30 \mathrm{~g}$. 



Рис. 1. Конструктивные исполнения микроблоков

Fig. 1. Constructive designs of microblocks

Корпус СВЧ-микроблока изготавливается из алюминиевого сплава Д16Т фрезерованием в мелкосерийном производстве или литьем под давлением (рис. 1). Внутри корпуса находится микроплата с электронными компонентами. Для герметизации корпуса пайкой легкоплавкими припоями на его поверхность наносят многослойное покрытие: никель - 15 мкм, медь - 6 мкм, покрытие олово-висмут толщиной 8-9 мкм.

В настоящее время до 40 \% металлостеклянных и металлокерамических корпусов БИС и микросборок герметизируется пайкой, достоинствами которой являются: ремонтопригодность изделия, невысокие температуры нагрева корпуса, некритичность к плоскопараллельности паяемых кромок, возможность групповой технологии. Применение традиционного процесса пайки на термостоле или паяльником имеет низкую производительность, использует в значительной мере ручной труд и не обеспечивает высокого качества паяемых соединений. Возникают трудности с использованием флюса и необходимостью удаления его остатков. Механизированная пайка в печи экономически оправдана лишь в крупносерийном производстве и требует больших энергозатрат.

Перспективным направлением в технологии производства РЭА является применение высокочастотной (ВЧ) пайки для герметизации корпусов БИС и микросборок. Воздействие энергии электромагнитных колебаний позволяет осуществить высокопроизводительный бесконтактный нагрев деталей и припоя с помощью наведенных в них вихревых токов ВЧ, активировать припой и улучшить его растекание по паяемым поверхностям. Качество паяемых соединений ВЧ-пайки зависит от следующих факторов:

- высокой скорости и регулируемости нагрева деталей и припоя по заданному термопрофилю;

- избирательности и локальности ВЧ-нагрева для исключения повреждения электронных компонентов;

- равномерности нагрева паяемых деталей для создания оптимальных условий физикохимического взаимодействия на границах припой-поверхность деталей [2].

Наиболее важные преимущества ВЧ-нагрева заключаются в следующем:

- энергия нагрева создается вихревыми токами непосредственно в изделии;

- возможны высокая плотность энергии и короткое время нагрева;

- локализация нагрева в пределах обрабатываемой зоны;

- возможность нагрева в любой среде, включая вакуум или инертный газ;

- высокая экологическая чистота нагрева;

$$
-661-
$$


- возможность использования электродинамических сил для улучшения растекания припоя, перемешивания расплава металла и т.д.

Существует большое разнообразие конструкций индукционных нагревательных устройств. Для сквозного нагрева проводящих тел круглого, квадратного и прямоугольного сечений применяют индукторы соленоидального типа (рис. $2 a$ ), плоских тел - в виде плоской спирали (рис. 2б). Для повышения эффективности ВЧ-нагрева применяют индукторы с магнитопроводом (рис. 3). Для нагрева колец, небольших плат, проводов используют индукционные устройства с замкнутой и разомкнутой магнитной цепью (рис. 4).

Наиболее оптимальным методом ВЧ-пайки является использование индуктора с магнитопроводом на металлокерамических материалах. Такой магнитопровод концентрирует магнитное поле в заданной зоне пайки, что позволяет не только осуществить высокопроизводительный бесконтактный нагрев деталей с помощью наведенных в них вихревых токов высокой частоты, но и активировать припой за счет пондеромоторных сил, а также улучшить его растекание по паяемым поверхностям.

Целью работы является исследование процесса герметизации корпусов СВЧ-микроблоков ВЧ-пайкой и оптимизация параметров ВЧ-нагрева. Необходимо при выборе генератора учитывать его рабочую частоту, которая определяет глубину проникновения поля внутрь корпуса.

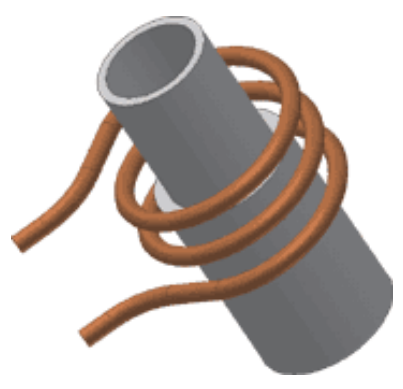

a

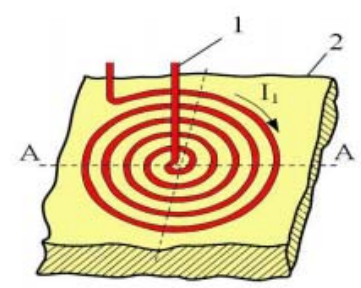

A-A

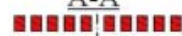

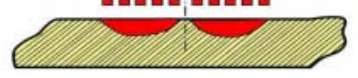

6

Рис. 2. Индуктор в виде соленоида (а) и в виде плоской спирали (б): 1 - индуктор, 2 - нагреваемое тело

Fig. 2. Inductor in the form of a solenoid (a), and in the form of a flat spiral (б): 1 - inductor, 2 - heated body

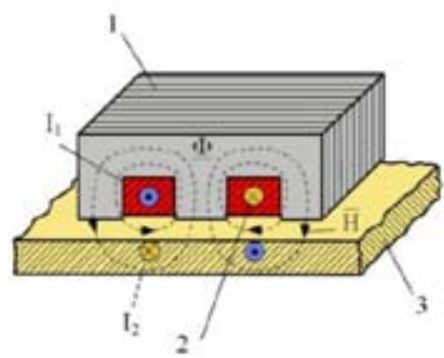

Рис. 3. Индуктор с магнитопроводом: 1 - магнитопровод; 2 - индуктор; 3 - нагреваемое тело

Fig. 3. Magnetic inductor: 1 - magnetic field; 2 -inductor; 3 - heated body 




a

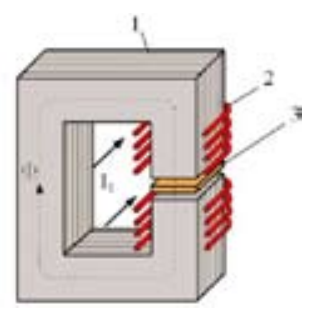

6

Рис. 4. Индукционные устройства с замкнутой (а) и разомкнутой (б) магнитной цепью: 1 - магнитопровод; 2 - индуктор; 3 - нагреваемое тело

Fig. 4. Induction devices with a closed (a) and open (б) magnetic circuit: 1 - magnetic field; 2 - inductor; 3 - heated body

В процессе герметизации корпуса микроблока необходимо, чтобы энергия электромагнитной волны была значительно меньше энергии деградации электронных компонентов внутри корпуса.

\section{Выбор частоты, расчет параметров индуктора и мощности ВЧ-нагрева}

При ВЧ-нагреве распределение напряженности электрического поля в проводящей среде имеет вид

$$
E=E_{0} \cdot \exp \left(\frac{-x}{\delta}\right)
$$

где $E_{0}$ - напряженность поля на поверхности; $\delta$ - глубина проникновения поля; $x$ - расстояние от поверхности детали.

Глубина проникновения поля зависит от частоты тока $f$, удельного электрического сопротивления материала $\rho$ и магнитной проницаемости $\mu[3]$ :

$$
\delta=\sqrt{\rho /\left(\pi \cdot f \cdot \mu_{0} \cdot \mu\right)},
$$

где $\mu_{0}$ - магнитная постоянная поля; $\rho$ - удельное электрическое сопротивление материала; $\mu$ магнитная проницаемость; $f$ - частота тока.

Следовательно, увеличение магнитной проницаемости и частоты тока приводит к более выраженному поверхностному эффекту.

Для расчета параметров индуктора использованы следующие исходные данные: материал корпуса и крышки - сплав Д16Т ( $\mu=1, \rho=5,2 \cdot 10^{-8}$ Ом'м); толщина крышки 2 мм; периметр паяного шва 245,8 мм; количество витков индуктора 6; диаметр трубки индуктора 5 мм; эффективное напряжение на индукторе 125 В. При этих условиях глубина проникновения составит доли миллиметра (рис. 5).

До 86 \% мощности нагрева создается в поверхностном слое проводящего тела толщиной $\delta$, где амплитуда напряженности поля уменьшается в $e$ раз. При пайке микроэлектронных устройств, содержащих внутри корпуса микроплату с элементами, чувствительными к электрической составляющей поля, энергия ЭМ наводки должна быть значительно меньше энергии деградации элементов, которая составляет 10-15 мкДж [4]. На глубине, равной 4-м толщинам скин-слоя $\delta$, напряженность поля ослаблена в 152 раз по сравнению с поверхностью и на поря-

$$
-663-
$$




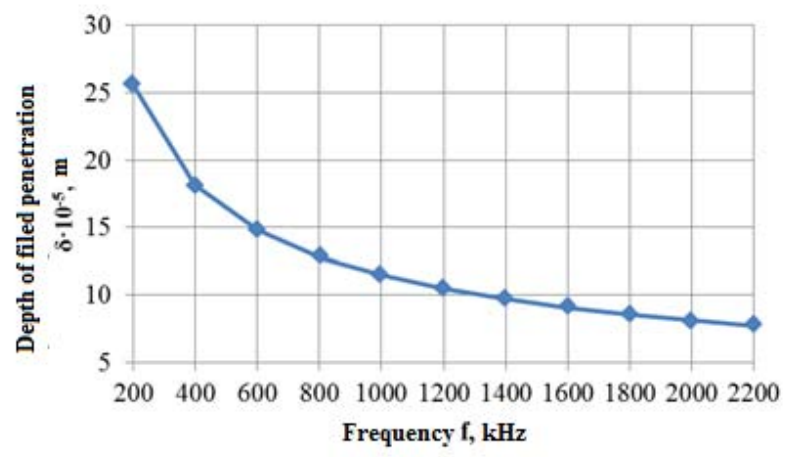

Рис. 5. Зависимость глубины проникновения поля от частоты

Fig. 5. Dependence of the depth of field penetration on frequency

док ниже напряженности наводок, приводящих к деградации элементов. Таким образом, выбор частоты при пайке микроэлектронных устройств необходимо осуществлять из условия:

$$
\delta \leq \mathrm{h} / 4
$$

где $h$ - толщина стенки корпуса.

Учитывая выражение (1), получим соотношение для нижней частоты тока:

$$
f_{\min } \geq 4.05 \cdot 10^{-6} \rho /\left(\mu h^{2}\right)^{.}
$$

Верхний предел частоты вытекает из требования максимальной величины термического КПД ВЧ-нагрева, при которой:

$$
\begin{aligned}
& \delta>\mathrm{h} / 8, \\
& f_{\max }<16.2 \cdot 10^{-6} \rho /\left(\mu h^{2}\right)
\end{aligned}
$$

Этим условиям удовлетворяет нагрев энергией ВЧ ЭМ колебаний в диапазоне частот 0,4-2,0 МГц. С повышением частоты локализуется тепловыделение и снижается температурное воздействие на изделие.

Энергия электрического поля определяется по формуле

$$
W=\frac{\varepsilon_{0} E^{2} V}{2}
$$

где $E$ - напряженность электрического поля; $V$ - объем поля, $\varepsilon_{0}=8,85 \cdot 10^{-12}$.

При напряжении на индукторе 1500 В и расстоянии между индуктором и деталью 2 мм напряженность электрического поля составит $750 \cdot \kappa \mathrm{B} / \mathrm{M}$. Тогда энергия электрического поля внутри индуктора объемом $125 \cdot 10^{-6} \mathrm{~m}^{3}$ будет равна 300 мкДж, а внутри корпуса микросборки с толщиной стенки 2 мм на частоте 2,2 МГц уменьшится в 152 раза и составит 1,97 мкДж.

Функциональные сбои у аналоговых ИС происходят при средних плотностях потока мощности порядка $10 \mathrm{mBT} / \mathrm{cm}^{2}(E=0,19$ кВ/м) [5]. Учитывая, что напряжение электрического поля, измеренное рамкой внутри корпуса, составляет $0,44 \mathrm{~B}$, напряженность электрического поля 
равна 0,0036 кВ/м. Таким образом, напряженность поля ослабляется в 63 раза и является безопасной для аналоговых ИС.

КПД индукционного нагрева определяется как отношение полезной мощности, выделяемой в нагреваемом объекте, к полной активной мощности [6].

$$
\eta=\frac{P_{2}}{P_{\Sigma}}=\frac{1}{1+\frac{\sqrt{\rho_{1} \mu_{1}}}{\sqrt{\rho_{2} \mu_{2}}}}
$$

где $P_{2}$ - активная мощность в загрузке; $P_{\Sigma}$ - суммарная мощность системы; $\rho_{1}, \rho_{2}$ - удельные электрические сопротивления материала индуктора и детали соответственно; $\mu_{1}$ и $\mu_{2}$ - магнитные проницаемости материала индуктора и детали.

При небольшом различии в удельных электрических сопротивлениях индуктора и детали и ее диамагнитных свойствах КПД индукционного нагрева не свыше 0,6. Для повышения эффективности нагрева используют эффект близости, который заключается в стягивании вихревого тока детали под поверхность индуктора и в концентрации тока индуктора на поверхности проводника, обращенной к индуктору. При малых зазорах между индуктором и деталью ( $h \leq 2-4$ мм) ширина зоны нагрева на поверхности детали определяется проекцией диаметра индуктора. В случае ярко выраженного эффекта близости можно предположить, что индукционный ток в детали протекает в малой зоне, ограниченной глубиной проникновения и размерами индуктора, сопротивление которой равно:

$$
R_{\mathrm{д}}=\rho \frac{l}{\delta H}
$$

где $l$ - периметр детали, $H$ - ширина зоны нагрева.

Электрическое сопротивление токам ВЧ в зоне нагрева можно определить из предположения, что ширина зоны нагрева при малых величинах зазора h определяется проекцией диа-

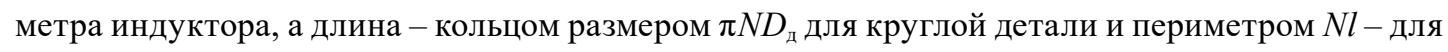
прямоугольной (рис. 6) [7]:

$$
R_{\text {д }}=2 \cdot 10^{-3} \cdot \frac{N l}{d_{\text {и }}} \cdot \sqrt{\rho_{\text {д }} f \mu}=(0,08 \div 0,19) \text { Ом },
$$

где $N$ - количество витков; $l$ - периметр детали в зоне нагрева; $d_{\text {и }}$ диаметр трубки индуктора; $\rho_{д}-$ удельное электрическое сопротивление детали.

Эффективная мощность ВЧ-нагрева в общем случае равна [8]:

$$
P_{\ni \phi}=\frac{U_{\ni \phi}^{2} \cdot \cos \varphi \cdot \eta}{R_{\text {д }}}=(0,8-2,0) \kappa \mathrm{BT} .
$$

Из расчетов получилось, что для пайки ВЧ-нагревом микроблоков необходимо поддерживать частоту в диапазоне 0,4-2,0 МГц. КПД процесса составляет 0,6. Электрическое сопротивление токам ВЧ в зоне нагрева в диапазоне данных частот равно 0,08-0,19 Ом. Для нагрева корпуса с данным электрическим сопротивлением и КПД необходимо поддерживать эффективную мощность ВЧ-нагрева в диапазоне $0,8-2$ кВт.

$$
-665-
$$




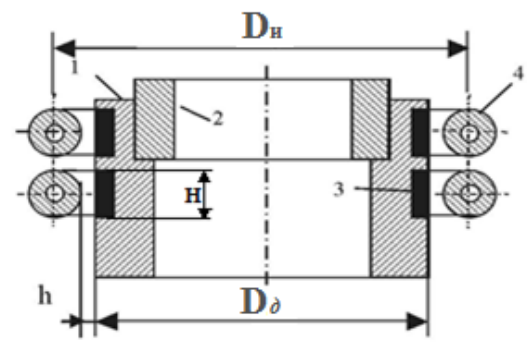

Рис. 6. Схема ВЧ-нагрева при эффекте близости: 1, 2 - детали; 3 - зона нагрева; 4 - индуктор

Fig. 6. HF heating scheme with proximity effect: 1, 2-details; 3 - heating zone; 4 -inductor

\section{Разработка методики исследования ВЧ-пайки корпусов микроблоков}

Для качественной герметизации СВЧ-микроблоков ВЧ-пайкой необходимо обеспечить необходимый температурный профиль (рис. 7). Он состоит из трех участков: нагрев до температуры плавления припоя, пайка и охлаждение.

При ВЧ-нагреве важно оперативно регулировать скорость нагрева так, чтобы паяемые детали и припой одновременно достигали температуры пайки. На индуктор подают ВЧнапряжение и нагревают изделие (участок от $25^{\circ} \mathrm{C}$ до $T_{\text {smax }}$ на рис. 7). Скорость нагрева составляет порядка $2 \div 3{ }^{\circ} \mathrm{C} / \mathrm{c}$.

После расплавления припоя $\left(T_{L}\right)$ снижают интенсивность ВЧ-нагрева в зависимости от требуемого температурного режима процесса пайки (участок $T_{L}-T_{p}$ ), что позволяет избежать перегрева припоя, а также снизить нагрев изделия. Затем ВЧ-напряжение отключают и изделие охлаждают. В табл. 1 указаны предельные значения параметров для двух припоев [2].

Схема проведения эксперимента представлена на рис. 8. Для герметизации корпуса пайкой легкоплавкими припоями на его поверхность наносят многослойное покрытие: никель -15 мкм, медь - 6 мкм, покрытие олово-висмут толщиной 8-9 мкм.

Перед пайкой соединяемые поверхности подвергались горячему облуживанию припоем с помощью электрического паяльника мощностью 50 Вт. После облуживания паяемых поверх-

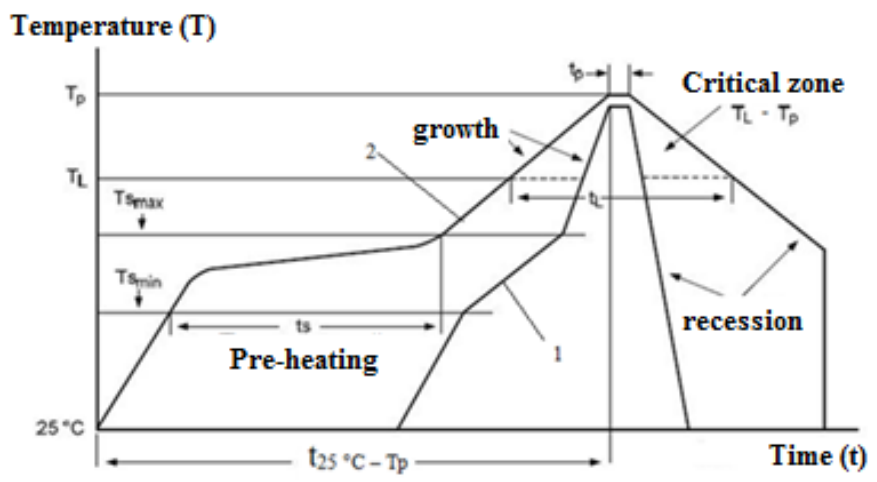

Рис. 7. Рекомендуемый профиль пайки: 1 - припой $\mathrm{SnPb} ; 2$ - припой без $\mathrm{Pb}$

Fig. 7. Recommend solder profile: 1 - solder $\mathrm{SnPb} ; 2$ - solder without $\mathrm{Pb}$ 
Таблица 1. Предельные значения для профилей

Table 1. Limit values for profiles

\begin{tabular}{|c|c|c|}
\hline Свойство профиля & $\begin{array}{c}\mathrm{SnPb} \text { эвтектический } \\
\text { монтаж }\end{array}$ & Монтаж без $\mathrm{Pb}$ \\
\hline Средняя скорость роста $\left(T_{s \max }\right.$ до $\left.T_{p}\right)$ & максимум $3^{\circ} \mathrm{C} / \mathrm{c}$ & максимум $3{ }^{\circ} \mathrm{C} / \mathrm{c}$ \\
\hline $\begin{array}{l}\text { Предварительный нагрев: } \\
-\quad \text { Минимальная температура }\left(T_{s \min }\right) \\
-\quad \text { Максимальная температура }\left(T_{s \max }\right) \\
-\quad \text { Время }\left(t_{s \min } \text { до } t_{s \max }\right)\end{array}$ & $\begin{array}{c}100^{\circ} \mathrm{C} \\
150{ }^{\circ} \mathrm{C} \\
\text { от } 40 \text { до } 70 \mathrm{c}\end{array}$ & $\begin{array}{c}150^{\circ} \mathrm{C} \\
200^{\circ} \mathrm{C} \\
\text { от } 60 \mathrm{c} \text { до } 100 \mathrm{c}\end{array}$ \\
\hline $\begin{array}{l}\text { Верхняя граница температуры } \\
-\quad \text { Температура }\left(T_{L}\right) \\
-\quad \text { Время }\left(t_{L}\right)\end{array}$ & $\begin{array}{c}183^{\circ} \mathrm{C} \\
\text { от } 60 \text { до } 150 \mathrm{c}\end{array}$ & $\begin{array}{c}217^{\circ} \mathrm{C} \\
\text { от } 60 \text { до } 150 \mathrm{c}\end{array}$ \\
\hline Предельная/классификационная температура $\left(T_{p}\right)$ & $235^{\circ} \mathrm{C}$ & $260^{\circ} \mathrm{C}$ \\
\hline Число возможных циклов рециркуляции & 3 & 3 \\
\hline $\begin{array}{l}\text { Время в пределах } 5^{\circ} \mathrm{C} \text { фактического максимума } \\
\text { температуры }\end{array}$ & от 10 до $30 \mathrm{c}$ & от 20 до $40 \mathrm{c}$ \\
\hline Скорость спада температуры & максимум $6^{\circ} \mathrm{C} / \mathrm{c}$ & максимум $6{ }^{\circ} \mathrm{C} / \mathrm{c}$ \\
\hline Время от $25^{\circ} \mathrm{C}$ до максимальной температуры & максимум 6 мин & максимум 8 мин \\
\hline
\end{tabular}

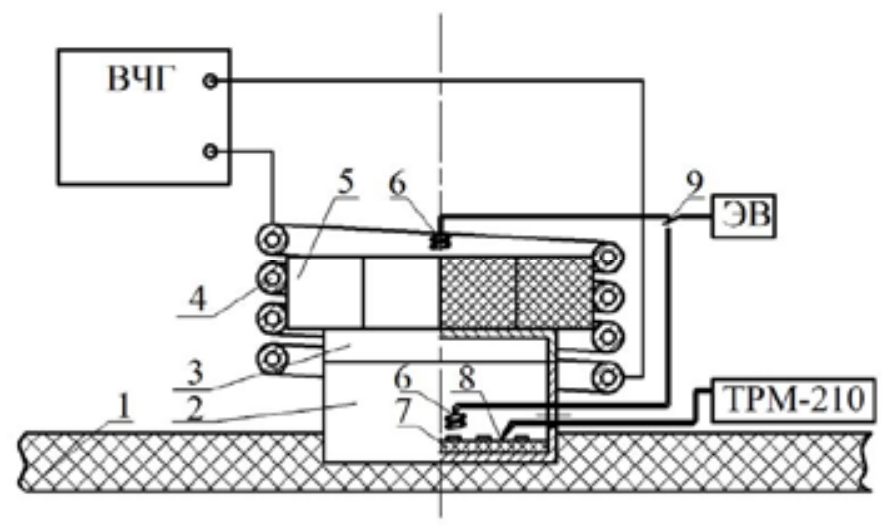

Рис. 8. Схема герметизации корпусов СВЧ-микроблоков ВЧ-пайкой: 1 - основание; 2 - корпус; 3 - крышка; 4 - индуктор; 5 - магнитопровод; 6 - измерительная рамка; 7 - микроплата; 8 - термопара; 9 - переключатель

Fig. 8. The scheme of hermetic sealing of the hulls of microwave microblocks by soldering: 1 - base; 2 - housing; 3 - cap; 4 -inductor; 5 - magnetic core; 6 - measuring frame; 7 - microplate; 8 -thermocouple; 9 - switch

ностей остатки флюса удалялись промывкой в горячей воде. В качестве источника высокочастотной энергии использовался высокочастотный ламповый генератор ВЧГ2-1/1.

Корпус с герметизируемой ИС устанавливался в вырезанное окно в изоляционном основании, на корпус надевалась крышка. После установки крышки подводился индуктор, на который подавалось напряжение ВЧ от вторичной обмотки воздушного трансформатора, и осуществлялся нагрев поверхности крышки. Время пайки определялось визуально, после расплавления и опускания крышки давалась выдержка 1-2 с. Паяное соединение крышки с корпусом осуществлялось за счет слоя предварительного лужения. Время на-

$$
-667-
$$


грева ТВЧ регистрировалось секундомером. В процессе экспериментов измерялась температура нагрева подложки ИС, температура пайки, напряженность внутри индуктора и внутри корпуса.

Измерительная рамка размещалась как внутри индуктора, так и внутри корпуса микроблока и соединялась с электронным вольтметром. В измерительной рамке наводилась ЭДС, величина которой равна:

$$
\varepsilon=\mu_{0} \omega \cdot n \pi R^{2} H
$$

где $\mu_{0}=4 \pi \cdot 10^{-7}$ Гн/м; $\omega-$ круговая частота; $n-$ число витков; $R-$ радиус контура круглой рамки; $H$ - напряженность магнитного поля.

Для квадратной рамки формула для расчета напряженности поля имеет вид

$$
H=1,26 \frac{\varepsilon(\mathrm{B})}{f(\mathrm{M \Gamma ц}) \cdot a^{2}\left(\mathrm{MM}^{2}\right) \cdot n} \cdot 10^{5} \mathrm{~A} / \mathrm{M},
$$

где $a^{2}$ - площадь одного витка квадратной рамки, мм².

Зависимости температуры в зоне пайки крышки с корпусом, измеренные с помощью термопары, приведены для различных конструкций индуктора на рис. 9. На рис. 10 показаны зависимости напряженности магнитного поля от мощности ВЧ-генератора для различных конструкций индуктора.

Запаянные образцы подвергались испытаниям на герметичность с помощью промышленного передвижного течеискателя ПТИ-10. Использовался разрушающий метод определе-

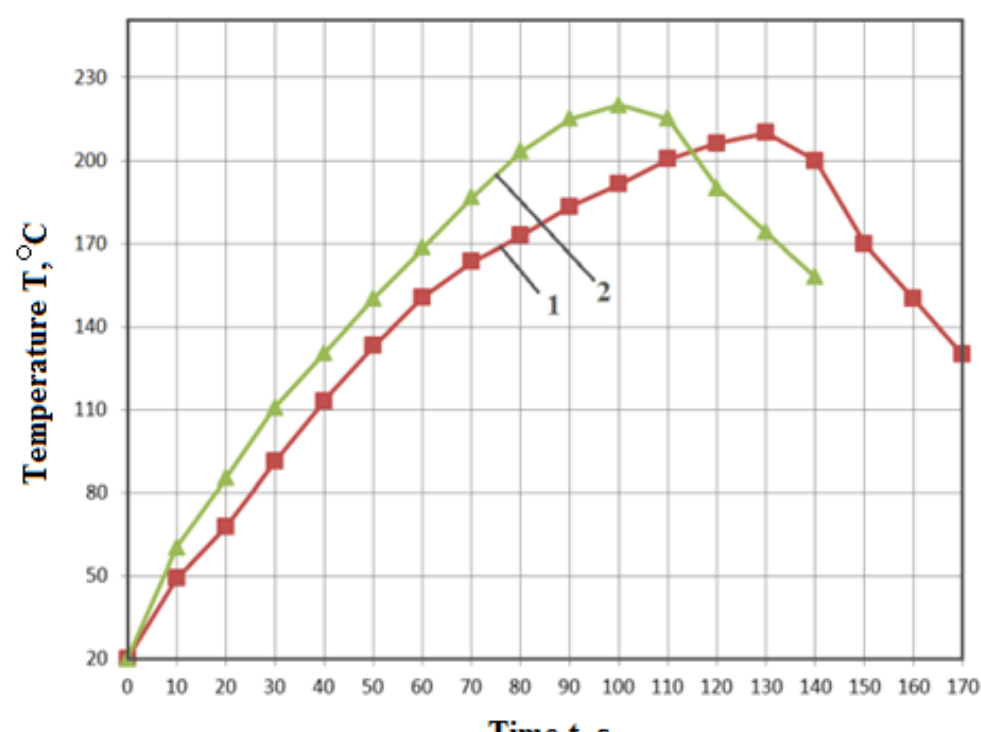

Time t, s

Рис. 9. Зависимости температуры в зоне ВЧ-пайки от времени для шестивиткового индуктора: 1 - без магнитопровода; 2 - с ферритовым магнитопроводом

Fig. 9. Temperature dependence in the HF soldering zone versus time for a six-turn inductor: 1 - without the magnrtic circuit; 2 - with ferrite core 




Рис. 10. Зависимости напряженности магнитного поля от мощности ВЧ-генератора для шестивиткового индуктора: 1 - без магнитопровода; 2 - с ферритовым магнитопроводом

Fig. 10. Dependence of the intensity of the magnetic filed on the power of the HF generator for a six-turn inductor: 1 - without the magnrtic circuit; 2 - with ferrite core

ния качества герметизации. Для этого в крышке корпуса сверлилось отверстие диаметром 2-3 мм. Корпус устанавливался в специальном приспособлении, соединенном вакуумными шлангами с течеискателем ПТИ-10 и вакуумным насосом. Из корпуса ИС откачивался воздух до давления не более (8-5)·10-2 мм рт.ст., после чего вакуумный насос отключался. Откачанный объем корпуса обдувался гелием. Количественная оценка герметичности корпуса ИС производилась по шкале прибора ВПУ-3, установленного на выносном пульте управления течеискателем. Срезы паяных соединений исследовались на металлографическом микроскопе МИМ-8.

На рис. 11 представлена зависимость температуры подложки, находящейся внутри корпуса, от времени для шестивиткового индуктора. В ходе исследований, представленных на данной зависимости, корпус нагревался до температуры $230^{\circ} \mathrm{C}$.

Анализ зависимостей показывает, что применение ферритового магнитопровода внутри индуктора концентрирует напряженность магнитного поля при одинаковой мощности ВЧнагрева в 1,2-1,3 раза, при этом скорость нагрева увеличивается во столько же раз. При одной и той же мощности напряженность внутри корпуса составляет $0,0025 \cdot 10^{5} \mathrm{~A} / \mathrm{M}$, что в 44 раза меньше, чем снаружи. Подложка не испытывает перегрева во время герметизации корпусов СВЧ-микроблоков ВЧ-пайкой.

Таким образом, применение ВЧ-нагрева в сочетании с ферритовым магнитопроводом при герметизации пайкой корпусов микроблоков, изготовленных из диамагнитных сплавов, позволяет увеличить производительность процесса в 1,2-1.3 раза, повысить надежность микроэлектронных приборов, а также применить бессвинцовые припои взамен дефицитных оловяннокадмиевых и оловянно-висмутовых припоев.

$$
-669-
$$




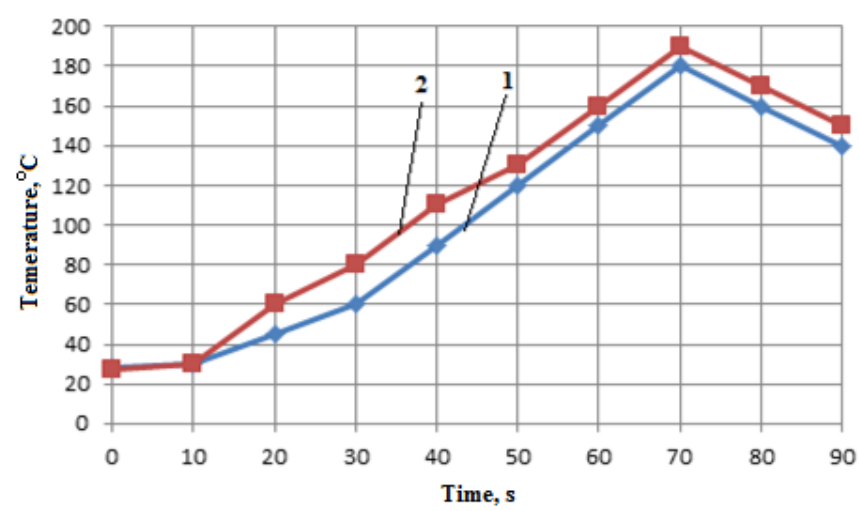

Рис. 11. Зависимости температуры подложки, находящейся внутри корпуса, от времени для шестивиткового индуктора: 1 - без магнитопровода; 2 - с ферритовым магнитопроводом

Fig. 11. The dependence of the temperature of the substrate inside the ousing on the time for a six-turn inductor: 1 - without the magnrtic circuit; 2 - with ferrite core

\section{Список литературы}

[1] Климачев И. И., Иовдальский И. И. СВЧ ГИС. Основы технологии и конструирования. M.: Техносфера, 2006. 351 c. [Klimachev I.I., Iovdalysky I.I. Microwave Hybrid Integrated Circuits. Bases of technology and designing. Moscow, Technosphera, 2006. (in Russian)].

[2] Ланин В. Л., Достанко А. П., Телеш Е. В. Формирование токопроводящих контактных соединений в изделиях электроники. Минск: Изд. центр БГУ, 2007. 574 с. [Lanin V.L., Dostanko A.P., Telesh E.V. Formation of current-carrying contact connection in electronics products. Minsk, Publ. center of the BSU, 2007 (in Russian)].

[3] Rapoport E., Pleshivtseva Y. Optimal Control of Induction Heating Processes, NY: CRC Press, 2007.

[4] Ricketts L.W., Bridges J.E., Miletta J. EMP radiation and protective techniques. N.J., Join Wiley@ Sons, Inc.1976.

[5] Ключник А.В., Пирогов Ю. А., Солодов А. В. Обратимые отказы интегральных микросхем в полях радиоизлучений. Журнал радиоэлектроники, 2013(1). http://www.modtop.ru/ node/33849. [Kluchnic A.V., Pirogov J.A., Solodov A.V. Reversible refusals of integrated circuits in fields of radioemissions. Radio Electronic Journal. 2013 (1). ( in Russian)].

[6] Metaxas A.C. Foundation of Electroheat. NY: John Willey @ Sons, 1996.

[7] Кувалдин А.Б. Особенности расчета параметров электромагнитного нагрева в ферромагнитной стали. Промышленный электрообогрев и электроотопление, 2014 (2) 26-30. [Kuvaldin A.B. Calculation Features of Electromagnetic Heating Parameters in Ferromagnetic Steel. Industrial electrical heating and electroheating, 2014 (2) 26-30 (in Russian)].

[8] Lanin V.L. Application of the concentrated power streams in electronics industry. Saarbrucken, Scholars' Press, 2015.194 p. 